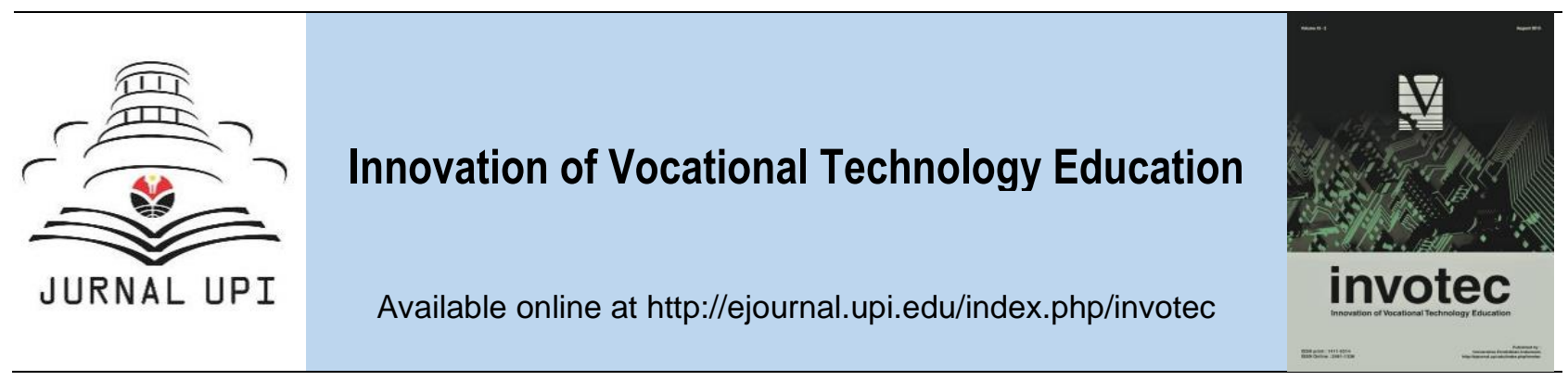

\title{
Development of Response Measurement Instruments Students on Learning
}

Karpin and A. Juwaedah

Universitas Pendidikan Indonesia, Indonesia

\section{ARTICLE INFO}

Article history:

Received 10 January 2019

Received in revised form 9 February

2019

Accepted 23 February 2019

Available online 28 February 2019

Keywords:

instrument of learning type,

instrument of learning

strategy, instrument of student

responses to learning

Corresponding author:

karpin@upi.edu
A B S T R A C T

The research aims has measured student responses to learning process on what a significant impact on the lectures desire to implement various learning innovation. This article is intended to find out developing instruments for measuring student responses to learning based-on Hinkin's model about instrument developing process. This research used quantitative approach in which data has collected 170 people as a sample, they are students of culinary study program at Indonesia University of Education. The instrument of this research used questionnaires contains three variables that are; the types of learning, the learning strategies, and the students responses of learning. This research found that the results of factor analysis on the indicators of the research variable are obtained; the factors from the learning type variable are constructive-interactive-passive-and active. The factors formed from the variable learning strategies are explanation and facilitation; and the factors formed by student responses to learning are value-positivity-distraction-and participation. The instrument that had been developed would be relevant for broader scope and context for learning other fields.

\section{Introduction}

Awareness of education practitioners to reform science, technology, engineering, and mathematics education has provided much inspiration to learning innovations. Many studies have been conducted in order to solve learning problems. The research was about innovation and implementation of learning models, learning approaches and learning strategies, learning media, learning implementation, planing models, organizing learning materials and learning outcomes assessment systems. However, the adoption of research results on learning practices by learning facilitators seems slow.

The results of the study provide very important suggestions that the response of learning participants to the learning process has a significant impact on the desire of the learning facilitator (lecturer) for adopted of various types of learning (DeMonbrun, 2017). Active learning is very effective for providing learning to diverse students (Prince, 2004), and for increasing student retention rates in learning programs (Prince \& Felder, 2006). Active learning requires students to play an active role in learning activities in the classroom (Felder and Brent, 2009).

Some researchers have identified a number of obstacles presented by lecturers who can help explain the slow rate of adoption of learning innovations. Among the most commonly presented 
obstacles were concerns that students will refuse, or respond negatively to the implementation of learning innovations (Daly and Richardson, 2014). In reality, students' responses to new and different types of learning can be positive if students are involved in the implementation of learning innovation activities (Livingstone and Lynch, 2000). Concern about negative responses resulted in lecturers not adopting new and different types of learning. In order to increase the adoption of learning innovation results by lecturers, information is needed about student responses to the implementation of learning innovation outcomes. Data on student response to learning must be valid. Valid data can only be obtained by using a valid instrument, so an instrument for measuring student response to the learning process is needed.

The research focused on developing instruments for measuring student responses to the learning process. The urgency of the research conducted was: the instrument for measuring student responses to the learning process produced can be used by researchers and educational practitioners to study student responses to types of learning; a framework with the aim of connecting between types of learning, learning strategies, and student responses; and the results of measuring student responses to the learning process can be used as a reference for improving learning and in turn will improve the quality of student learning outcomes.

\section{Method}

The American Psychological Association (APA, 1995) states that the exact operational definition of the construct size must include content validity, validity related to criteria, and internal consistency. There are three main aspects of construct validation: (a) determine the domain of the construct, (b) empirically determine the extent to which the item measures the domain, and (c) examine the extent to which the results produce predictable results from the theoretical hypothesis. The process of developing Student Response Measuring Instruments for Learning adapted from Hinkin (1998).

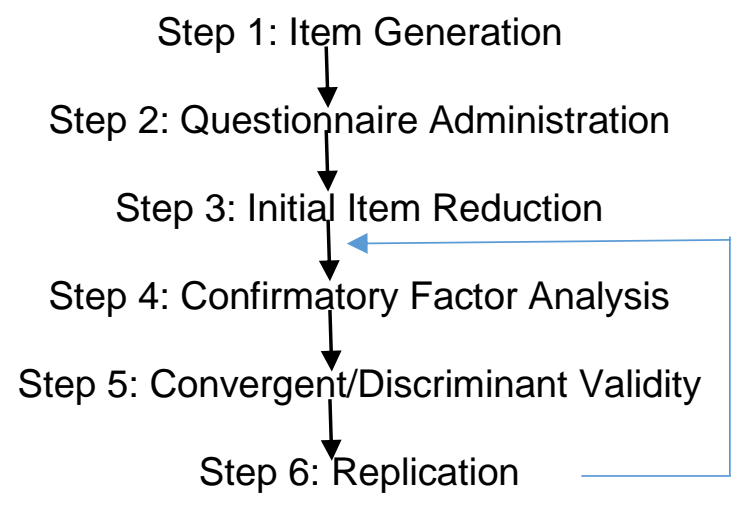

Figure 1. Scale Development Process

Steps for developing instruments. First steps, Generation items, create items and develop constructs for instruments; the process is from the literature review of instructional types, student responses, and strategies for activating classroom activities. The item must be clearly related to the theoretical construct to be assessed. The second step, the administration questionnaire, tests the validity by observing classroom learning. The selection of the right type of sample is very important to ensure sufficient variation in responses (student response). The third step, initial item reduction, reporting results in developing new sizes. Consistency of internal reliability is a necessary condition. The focus of this section is on reliability assessment. The fourth step, research activities to quantitatively assess the quality of the factor structure. The fifth step, construct validity of a measure is the ultimate goal of scale development. The sixth step, replication, modifying instruments and replicating findings through administration of complete instruments.

The subject of the study was the development of instruments to measure student responses to learning. The study was conducted at the Culinary Education Study Programme, Home Economic Department, Indonesia University of Education. For the purposes of instrument analysis that was made in the initial stages of the study, the sample was taken by proportional random sampling 
technique. The instrument for collecting data used a questionnaire made at the initial stage of the research. The instrument was made based on the results of construct development based on the results of the literature review on the type of learning, student responses to learning and strategies to activate students in the classroom.

\section{Result and Discussion}

\section{a. Type of learning}

The results of instrument development on research variables of learning types were obtained by 21 items. The items of the instrument were indicators of the types of learning conducted by lecturers. The items of the results of the development which were 21 indicators of types of learning were processed based on 170 responses from respondents. Data processing used factor analysis statistics.

The results of determining the indicators of learning type variables that are feasible to analyze are obtained results that all indicators can be analyzed further (MSA $>0.5$ ). The next step is the factoring process, which is the process of deriving one or more factors from all indicators of the learning type variable. In order to clarify the indicators of variables that enter into certain factors orthogonal rotation of the varimax method is carried out. Four factors are formed from the results of the factoring and orthogonal rotation of the varimax method. Grouping all learning type variable indicators into factors is determined by factor loadings statistics. Interpretation of four factors that have been formed, especially giving a name to the factors that have been formed which are considered to represent the indicators of the variable type of learning of these factors. The factors formed are given the name Constructive (factor 1), Interactive (factor 2), Passive (factor 3), and Active (factor 4). Factor reliability tests were carried out using Cronbach Alpha statistical tests. All factors formed from Construct Reliabilty are classified as reliable, because all factors have a Cronbach Alpha coefficient greater than 0.60.

The variance of student responses to the type of learning can be explained by the variance of the four factors formed. In learning lecturers must pay attention to four factors that contribute to the success of learning. Learning activities can be grouped as interactive, constructive, active, or passive learning processes. Passive learning is an event when students are expected to receive information passively from a lecturer. Active learning is an event when each student individually plays an active role in learning. Student activities in the learning process are divided into individual activities and activities carried out by two or more people. Activities carried out by two people or more are called interactive learning. Constructive learning is learning where students construct their own knowledge (self-discovery) rather than learning by being told what to do (Chi and Wylie 2014).

\section{b. Learning strategies}

The results of the development of instruments in the learning strategy research variables were 8 instruments. The items of the instrument were indicators of the learning strategies undertaken by the lecturer. The development instruments which are 8 indicators of learning strategies were processed based on 170 responses from respondents. Data processing used factor analysis statistics.

The results of the determination of indicators of learning strategy variables that were feasible to analyze obtained the results that all indicators could be analyzed further (MSA>0.5). The next step was a factoring process, namely the process of deriving one or more factors from all indicators of the learning strategy variable. In order to clarify the indicators of variables that enter into certain factors orthogonal rotation of the varimax method was carried out. Two factors formed from the results of the factoring and orthogonal rotation of the varimax method. Grouping all variable learning strategy indicators into factors was determined by statistical factor loadings. Interpretation of two factors that have been formed, especially giving a name to the factors that have been formed which were considered to represent the indicators of the variable type of learning of these factors. The factors formed were given the name Explanation (factor 1), and Facilitation (factor 2). Factor reliability tests were carried out using Cronbach Alpha statistical tests. All factors formed from Construct Reliabilty were classified as reliable, because all factors have a Cronbach Alpha coefficient greater than 0.60 . 
The variants of student responses to learning strategies can be explained by the two-factor variants that are formed. In learning lecturers must pay attention to two factors that contribute to the success of learning. Student responses to learning strategies can be used to reduce negative reactions and to understand the relative effectiveness of the strategies used. Three ways can be done by lecturers to reduce student resistance. First, the learning activities begin with an explanation of the learning objectives, the learning process that will be carried out and the difficulties that may arise. This was done so that students were ready to take part in learning and make them aware of the importance of the material to be learned. Second, asking for feedback from students as an improvement material and providing assistance to students in achieving learning goals. Third, facilitating students in learning by designing appropriate and challenging learning activities (Barneveld and Strobel, 2011).

\section{c. Student response to learning}

The results of the development of instruments on the research variables of student responses to learning were obtained by 18 instruments. The items of the instrument were indicators of student responses to the learning done by lecturers. The development instruments which are 18 indicators of student responses to learning are processed based on 170 responses from respondents. Data processing used factor analysis statistics.

The results of determining the indicators of student response variables to learning that were worthy of analysis obtained results that all indicators could be further analyzed (MSA $>0.5$ ). The next step was the factoring process, which is the process of deriving one or more factors from all the variable indicators of student responses to learning. In order to clarify the indicators of variables that enter into certain factors orthogonal rotation of the varimax method was carried out. Four factors were formed from the results of the factoring and orthogonal rotation of the varimax method. Grouping all indicators of student response variables to learning into factors was determined by factor loadings statistics. Interpretation of four factors that have been formed, especially giving a name to the factors that have been formed which were considered to represent the indicators of student response variables to the learning of these factors. The factors formed are named value (factor 1), positive (factor 2), distraction (factor 3), and participation (factor 4). Factor reliability tests were carried out using Cronbach Alpha statistical tests. All factors formed from Construct Reliabilty are classified as reliable, because all factors have a Cronbach Alpha coefficient greater than 0.60. The variants of student responses to learning activities can be explained by variants of the four factors formed. In learning the lecturer must pay attention to four factors that contribute to the success of the learning process. Student involvement in the learning process is grouped into three forms, namely cognitive involvement, affective emotional involvement, and behavioral involvement (Skinner and Pitzer, 2012).

Value factor is a measure of involvement of several cognitive elements that are influenced by students' thoughts, beliefs and expectations. Students see lecture activities as a valuable activity (cognitive). The positivity factor is a measure of student's affective emotional involvement based on various affective reactions to activities experienced by students during lectures. Students feel positive or negative feelings towards lectures (affective-emotional). Factor participation and distraction is a measure of student behavior involvement in participating in recovery, behavioral involvement in terms of participating or not participating or even showing rejection (behavior). Distraction is a form of negative participation. Based on the items of the results of the development, negative participation (refusal) is done by students in the form of: (1) open rejection by conducting non-constructive activities (open resistance); (2) rejecting in the form of diverting attention or doing activities that are not related to lectures (passive, non-verbal resistance); (3) refusal in the form of not seriously attending lectures (partial compliance).

\section{Conclusion}

This research has found strengthening Hinkin's model of instrument development process in a limited scope in the context of learning in the culinary education study program. The research describes the process of developing instruments and analyzing instrument that have been developed, and measured student responses to learning activities. The instruments developed measuring three constructs of learning responses, that are types of learning, learning strategies, and student responses to learning. Indicator of types of learning are constructive-interactive-passive, and 
active. Indicator of learning strategies are explanation and facilitation. Indicator of student responses to learning are value, positivity, distraction, and participation.

There are three practical implication for using instruments to measure student responses to learning. First, research has described the spectrum of learning activities in the instrument, the lectures can examine the type of learning uses and how important it is for students. Second, learning instrument has been arranged in learning instruments, lectures can use the learning program to support student involvement. Third, in the instrument there is a list of student responses to the type of learning, lectures can identify student behavior in response to the learning process.

\section{References}

American Psychological Association (APA). (1995). Standards for educational and psychological testing. Washington DC: APA.

Barneveld, A. V., and Strobel, J. (2011). Reports from teaching practice: Experiences and management of tensions encountered with PBL implementations in the early years of undergraduate engineering education. Paper presented at the Research in Engineering Education Symposium. Madrid: Spain.

Chi, M. T. H., and Wylie, R. (2014). The ICAP framework: Linking cognitive engagement to active learning outcomes. Educational Psychologist. 49(4): 219-243. http://dx.doi.org/10. 1080/00461520.2014.965823.

DeMonbrun, M., and Finelli, C. J. (2017). Creating an Instrument to Measure Student Response to Instructional Practices. Journal of Engineering Education. 106(2). http://wileyonlinelibrary.com/journal/jee.

Felder, R. M., and Brent, R. (2009). Active Learning: An Introduction. ASQ Higher Education Brief. 2(4). http://rube.asq.org/.

Hinkin, T. R. (1998). A brief tutorial on the development of measures for use in survey questionnaires. Organizational Research Methods. 1(1):104-121. http://dx.doi.org/10.1177/ 109442819800100106.

Livingstone, D., and Lynch, K. (2000). Group project work and student-centred active learning: Two different experiences. Studies in Higher Education. 25(3):325-345. http://dx.doi. org/10.1080/713696161.

Prince, M. J., and Felder, R. M. (2006). Inductive teaching and learning methods: Definitions, comparisons, and research bases. Journal of Engineering Education. 95(2):123-138. http:// dx.doi.org/10.1002/j.2168-9830.2006.tb00884.x.

Prince, M. (2004). Does active learning work? A review of the research. Journal of Engineering Education. 93(3):223-232. http://dx.doi.org/10.1002/j.21689830.2004. tb00809.

Skinner, E. A., and Pitzer, J. R. (2012). Developmental dynamics of student engagement, coping, and everyday resilience. In S. L. Christenson, A. L. Reschly, \& C. Wylie (Eds.). Handbook of research on student engagement (pp. 21-44). New York: Springer. http:// dx.doi.org/10.1007/978-1-4614-2018-7_2. 